\title{
Research Aвтіcle: Economic analysis of broiler production in Wardha district
}

\author{
Article Chronicle: \\ Received : \\ 18.02.2016; \\ Revised : \\ 01.07.2016; \\ Accepted : \\ 13.07.2016
}

KEY WoRDs:

Broiler, Costs,

Economics,

Production

\section{V.V. DAHAKE, K.R. MANKAWADE AND V.A. DESHMUKH}

SUMMARY : In this study an attempt has been made to study the economic analysis of broiler production in Wardha district with views to study the cost of broiler production. For the present study twenty broiler units from Wardha district were selected and grouped into small (1-2000 birds), medium (2001-4000 birds) and large (40001 birds and above). The study was based on the primary data of broiler production collected from the selected sample and economics of broiler production was worked out by using standard cost concept. The study revealed that, the cost of broiler production was highest in large unit (Rs. 3560277) followed by medium unit (Rs. 2526301) and small unit (Rs. 1124360), While the per kg cost of production was highest in small unit (Rs. 65.27) followed by medium (Rs. 63.29) and large (Rs. 61.44) The study also revealed that the benefit cost ratio was more in large unit (1.19) as compared to medium unit (1.15) and small unit (1.11)

How to cite this article : Dahake, V.V., Mankawade, K.R. and Deshmukh, V.A. (2016). Economic analysis of broiler production in Wardha district. Agric. Update, 11(3): 277-282, DOI : 10.15740/HAS/AU/11.3/277-282.

\section{V.V. DAHAKE}

Shri Sant Shankar

Maharaj College of

Agriculture, Pimpalkhuta, AKOLA (M.S.) INDIA

See end of the article for authors' affiliations 